\title{
Research Article \\ Formulation, Organoleptic Evaluation, and Acceptability of Various Teas from Underutilized Nutritious Herbs Compared with Marketed Chinese and Yellow Lipton Tea
}

Elijah Edache Ehoche ${ }^{*}$ (0)
Parth Patel 2
Chijioke Madu
Johnson Adejoh 3
1Department of Biochemistry, Federal
University of Technology Minna,
Minna, Nigeria
2Department of Pharmacy, Humera
Khan College of Pharmacy, Mumbai,
Maharashtra, India
3Department of Medical Biochemistry,
University of Abuja, Abuja, Nigeria
*email: elaijahee@gmail.com
Keywords:
Antioxidants
Herb
Nutrients
Tea
Sensory evaluation

\begin{abstract}
Herbal teas are nutrient, antioxidant, and hydration-rich brews made from herbs and spices and taken for various purposes. The objective of this study was to formulate tea from clove (Syzygium aromaticum), leaves of lemongrass (Cymbopogon citratus), guava (Psidium guajava), and moringa (Moringa oleifera), as well as compared with Chinese and yellow Lipton Tea. The samples were analyzed for comparative sensory analysis using the 7 points hedonic scale. The sensory evaluation result demonstrated that the color of the clove tea sample (5.87) was most acceptable by participants, while the lemongrass tea (4.46) sample was least acceptable amongst all the tea samples. The clove remained the most accepted tea for aroma (6.07), taste (5.92), texture (5.76), general appearance (5.74), and general acceptability (5.93), in 7 points hedonic scale. However, all tea samples were had significant acceptable scores above average $(p<0.05)$. Owing to the above results, these herbs can be successfully used to produce tea of relatively good quality to encourage herbs' local consumption and stay healthy.
\end{abstract}

Received: November $8^{\text {th }}, 2020$

Accepted: January 23rd, 2021

Published: February 28th, 2021

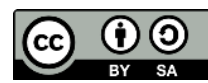

(c) 2021 Elijah Edache Ehoche, Parth Patel, Chijioke Madu, Johnson Adejoh. Published by Institute for Research and Community Services Universitas Muhammadiyah Palangkaraya. This is an Open Access article under the CC-BY-SA License https:// doi.org/10.33084/bjop.v4i1.1817

\section{INTRODUCTION}

Herbs have been generally used in history for various reasons ${ }^{1}$. These include ornaments and clothing but majorly processed in some crude forms as food and medicine and for relaxation. This is because of their ability to cure diseases, maintain optimal health, simplicity, cheapness, availability, inexpensively, acceptable taste and smell. Herbal teas or 'tisanes' are nutrient-hydration-and but straightforward-antioxidantrich brews made from herbs and spices. Furthermore, herbal teas help stimulate internal organs, boost immunity, enhance relaxation (sleep time and rest), promote energy and soundness, as well as general wellbeing 23 .

There has been more research and interest on regular tea 4 . However, there is more need to expand scientific investigations to other rich herbs like tea. This is even so, with the recent reoccurring outbreak of immunecompromising diseases of bacterial and viral sources to the extent of epidemics and pandemics that requires the need for not only immune boosters, anti-biotic activities but as to sustain the entire well-being of humankind 5 .

The natural compositions of notable aromatic, antioxidant, antimicrobial, and crucial therapeutic 
substances have placed herbs and teas as the lead for scientific investigations with the view of finding lasting solutions in the prevention, treatment, and management of various diseases like cancer, respiratory diseases, and many more ${ }^{6,7}$. This is especially beneficial when consumed regularly as food and not necessarily as medicine. The reason for selecting the herbs such as clove, lemongrass, guava, and moringa in this study is the plethora of therapeutic benefits they possess from the literature $^{6-9}$ though commonly underutilized, whereas Chinese and Lipton's tea is consumed by people globally ${ }^{6}$. These are popular and preferred brands by consumers; thus, they were used as control. Therefore, the current research's main aim was to evaluate the formulated tea samples' sensorial parameters and compare them with the commercially available Chinese and Lipton tea. This study represented the first evaluation of sensory properties and consumer acceptability of tea samples made from the clove.

\section{MATERIALS AND METHODS}

\section{Materials}

Fresh leaf samples of lemongrass and guava were obtained from household gardens around Maikunkele and Bosso towns in Bosso Local Government of Niger State, Nigeria, and determined at the Federal University of Technology, Minna. Dry clove, commercial Chinese tea from Camellia sinensis Chinese tea plant, and the yellow Lipton tea were obtained from Bosso market, Minna, Nigeria.

\section{Methods}

\section{Sample treatment}

The fresh leaf samples were allowed to air dry at room temperatures in the absence of sunlight for two weeks. All the dry samples were separately blended into a coarse chaffy powder. All the samples were kept in clean plastic bags and stored at room temperatures for use.

\section{Tea formulation}

Six tea diets were formulated from each sample $(2 \mathrm{~g})$ above. However, the sixth sample was a dry mixture of all the other five samples in the ratio of $1: 1: 1: 1: 1$. Each dry sample was steeped in $10 \mathrm{~mL}$ of boiled $\left(100^{\circ} \mathrm{C}\right)$ distilled water and allowed to stay for three minutes, after which the chaff was sieved out, and granulated sugar (2 g) was added to the filtrate $(4 \mathrm{~mL})$. The mixture was stirred and served for sensory analysis under hygienic conditions, as illustrated in Figure 1.

\section{Sensory analysis}

A 7-point hedonic scale was used to show the various samples' scoring using 150 scorers accustomed to tea drinking. The sensory evaluation was carried out among young adults (150 respondents) living around the Federal University of Technology and the University of Abuja, Nigeria. The various tea samples were scored for general appearance, taste, smell, color, texture, and general acceptability. Mean scores were calculated for each attribute.

\section{Statistical analysis}

The sensory scores include general appearance, taste, aroma, color, texture, and general acceptability, were analyzed using two-way ANOVA with levels of significance determined at $\mathrm{p}<0.05$. The means of the antioxidant and nutrient composition of the samples were also evaluated. The SPPS version 20 package was used for statistical analysis.

\section{Ethical approval}

Approved consent of the scorers was obtained from all respondents. The assessment is carried out according to ethical standards approved by The E3REE Research Committee under the Nigerian Regulatory Code for Human Subjects Research with Approval No. 0001. 


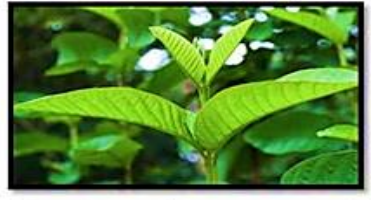

Fresh tea leaves sample

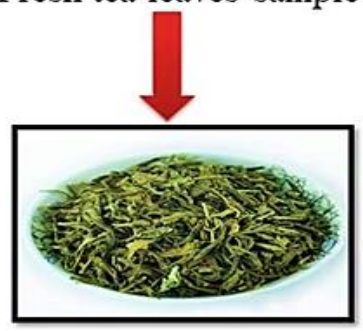

Dried at room temperature in absence of sunlight

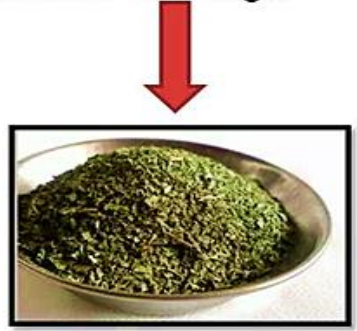

Powdered

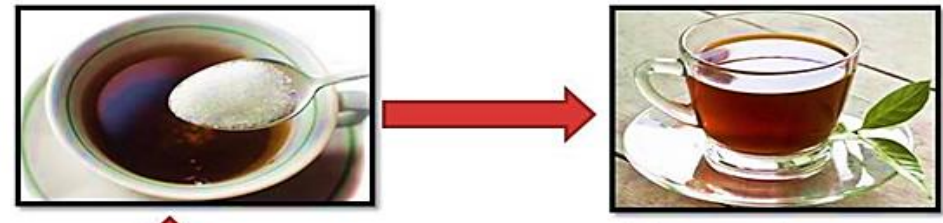

$2 \mathrm{~g}$ sugar was added to filtrate

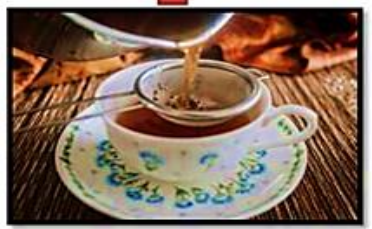

Strained

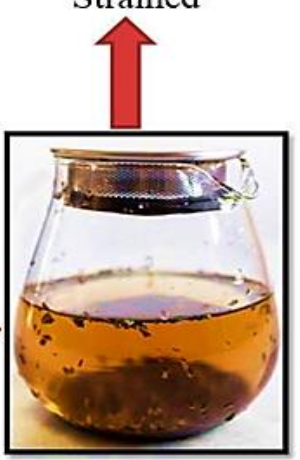

Tea sample was ready and served to participants

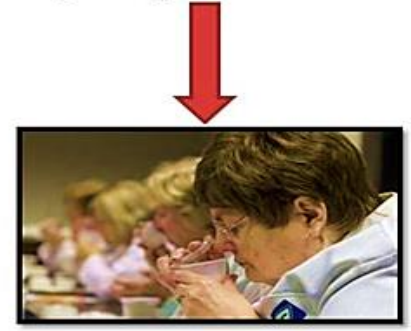

Sensory evaluation

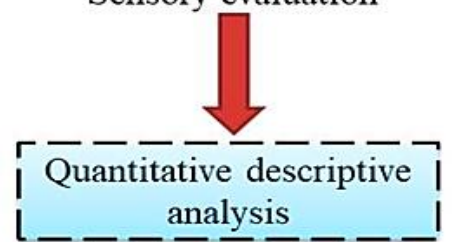

(3 minutes)

Figure 1. General method of preparation of tea samples

\section{RESULTS AND DISCUSSION}

Color

Participants' responses on the color of the prepared tea samples showed that the clove tea sample (5.87) was most acceptable, while the lemongrass tea (4.46) sample was least acceptable amongst all the tea samples (Table I). There was a significant difference in scores amongst the color of the tea samples. Score and acceptability for the aroma of the tea samples increased in order of lemongrass $(4.46)$ < guava leaves $(4.5)<$ Lipton $(4.7)<$ moringa $(4.79)<$ Chinese tea $(4.84)<$ mixture $(5)<$ clove (5.87). According to the literature, several amino acids in tea play an important role in imparting color to the tea. 'Brightness' and 'briskness of tea were due to compounds like theaflavin and thearubigins, which affect sensory characteristics ${ }^{10,11}$.

Aroma

Results illustrated in Table I show that clove tea had the highest mean score (6.07) as compared to control Lipton
(4.7) and Chinese tea (4.66), whereas the lowest mean score was assigned to the guava leaves tea sample (4.51) by consumers. There was a significant difference in scores amongst the aroma of the tea samples. Score and acceptability for the aroma of the tea samples increased in order guava leaves $(4.51)<$ lemongrass $(4.65)<$ Chinese tea $(4.66)<$ moringa $(4.69)<$ Lipton $(4.7)<$ mixture $(4.93)$ $<$ clove (6.07). As guava leaves tea samples were also the least preferred by consumers in terms of overall appearance (4.6), they remained the lowest in the aroma.

Taste

The result shows the variation in taste acceptability amongst tea samples (Table I). There was a significant difference in scores amongst the general acceptability of the tea samples. The highest mean score was assigned to clove tea (5.92), whereas the lowest score was assigned to Chinese tea (4.47). Compared to marketed tea formulations, Lipton and Chinese tea, the clove tea sample being the highest scored, was most preferred by 
participants. Score and acceptability for a taste of the tea samples increased in order Chinese tea < Lipton < moringa $<$ lemongrass < guava leaves $<$ mixture $<$ clove. Constituents such as tannins, catechins, amino acids contribute to the flavor of the tea. Catechins were predominantly known to contribute to $70-75 \%$ of bitterness and astringency, whereas caffeine and tannins were responsible for astringent or pungent taste. The brothy and the sweet taste was due to amino acids ${ }^{12-14}$.

\section{Texture}

The clove tea sample had the highest mean score (5.76) and remained the most preferred by consumers, while the lemongrass tea sample had received the lowest mean score (4.48). Lemongrass tea sample was also least scored and preferred in general appearance (4.63) and color (4.46). There was a significant difference in scores amongst the texture of the tea samples (Table I). Score and acceptability for texture of the tea samples increased in order lemongrass $(4.48)$ < guava leaves $(4.5)<$ Lipton $(4.64)<$ mixture $(4.74)<$ moringa $(4.76)<$ Chinese tea $(4.78)<$ clove $(5.76)$.

\section{General appearance}

Results show that the clove tea sample was assigned the highest mean score in general appearance (5.74), while the guava tea sample had received the lowest score (4.6), as shown in Table I. There was a significant difference in scores amongst the general appearance of the tea samples. Score and acceptability for the general appearance of the tea samples increased in order guava leaves $<$ lemongrass $<$ moringa $<$ Lipton $<$ Chinese tea $<$ mixture < clove.

\section{General acceptability}

As expected, the clove tea sample had the highest mean score (5.93), whereas lemongrass was assigned the lowest score (4.61). There was a significant difference in scores amongst the tea samples' general acceptability (Table I). Score and acceptability for the general appearance of the tea samples increased in order lemongrass (4.61) < guava leaves $(4.85)<$ Lipton $(4.85)<$ moringa $(4.88)<$ Chinese tea $(4.96)<$ mixture $(4.96)$ < clove (5.93). Interestingly, both Lipton (4.85) and guava leaves (4.85) tea samples were almost equally acceptable and preferred by participants. Similar results were obtained for Chinese tea (4.96) and mixture (4.96) sample tea.

Table I. Values of sensory attributes of formulated tea samples with comparison to the commercial Lipton and Chinese tea sample

\begin{tabular}{|c|c|c|c|c|c|c|}
\hline Sample & $\mathrm{C}$ & $\mathbf{A}$ & Ta & $\mathrm{Te}$ & Gap & Gac \\
\hline \multirow[t]{2}{*}{ Clove } & $5.87 \pm$ & $6.07 \pm$ & $5.92 \pm$ & $5.76 \pm$ & $5.74 \pm$ & $5.93 \pm$ \\
\hline & $0.98^{\text {atododef }}$ & 0.95 atoded & $1.08^{\text {athodefg }}$ & $1.25^{\text {atodof }}$ & 1.06 aldode & 1.07abodof \\
\hline \multirow{4}{*}{$\begin{array}{l}\text { Lemon- } \\
\text { grass } \\
\text { Guava }\end{array}$} & $4.46 \pm$ & $4.65 \pm$ & $4.75 \pm$ & $4.48 \pm$ & $4.63 \pm$ & $4.61 \pm$ \\
\hline & $1.21^{\mathrm{c}}$ & $1.32^{c}$ & $1.18^{c}$ & $1.3^{c}$ & $1.07 \mathrm{c}$ & $1.32^{c}$ \\
\hline & $4.5 \pm$ & $4.51 \pm$ & $4.76 \pm$ & $4.5 \pm$ & $4.6 \pm$ & $4.85 \pm$ \\
\hline & $1.4^{\mathrm{bg}}$ & $1.14 \mathrm{bg}$ & $1.34^{b}$ & $1.15^{b}$ & $1.16^{\mathrm{b}}$ & $1.25^{\mathrm{b}}$ \\
\hline \multirow[t]{2}{*}{ Moringa } & $4.79 \pm$ & $4.69 \pm$ & $4.71 \pm$ & $4.76 \pm$ & $4.68 \pm$ & $4.88 \pm$ \\
\hline & $1.27^{\mathrm{F}}$ & $1.34^{\mathrm{f}}$ & $1.33^{f}$ & $1.18^{f}$ & $1.11^{\mathrm{f}}$ & $1.23^{f}$ \\
\hline \multirow[t]{2}{*}{ Mixture } & $5.00 \pm$ & $4.93 \pm$ & $4.86 \pm$ & $4.74 \pm$ & $4.89 \pm$ & $4.96 \pm$ \\
\hline & $1.59 \mathrm{gg}$ & $1.63 \mathrm{eg}$ & $1.51^{\mathrm{eg}}$ & $1.52 \mathrm{e}$ & $1.44 \mathrm{e}$ & $1.41^{\mathrm{e}}$ \\
\hline \multirow[t]{2}{*}{ Lipton } & $4.7 \pm$ & $4.7 \pm$ & $4.7 \pm$ & $4.64 \pm$ & $4.7 \pm$ & $4.85 \pm$ \\
\hline & $1.05^{\mathrm{d}}$ & $0.76^{\mathrm{d}}$ & $0.74^{\mathrm{d}}$ & $0.73^{\mathrm{d}}$ & $0.88^{\mathrm{d}}$ & $1.04^{\mathrm{d}}$ \\
\hline Chinese & $4.84 \pm$ & $4.66 \pm$ & $4.47 \pm$ & $4.78 \pm$ & $4.8 \pm$ & $4.96 \pm$ \\
\hline tea & 1.09 & $1.13^{a}$ & $1.12^{\mathrm{ag}}$ & $1.12^{\mathrm{a}}$ & $0.94^{a}$ & $1.15^{a}$ \\
\hline
\end{tabular}

C: color; A: aroma; Ta: taste; Te: texture; Gap: general appearance; Gac: general acceptability. Alphabetical superscript signifies the mean difference significant at 0.05 level (95\%). Values with different superscript within a column were significantly different at $\mathrm{p}<0.05$

The current study's primary objective was to formulate tea samples of various herbs and compare them with commercially available Lipton and Chinese tea samples. According to the literature, this study is the first to select some of the herbs used in previous studies. The findings of this study suggest that among all the tea samples, the clove tea sample was the most accepted, preferred, and highest scored in terms of color (5.87), aroma (6.07), texture (5.76), taste (5.92), general appearance (5.74), and overall acceptability (5.93), whereas, lemongrass was least accepted, preferred, and lowest scored in color (4.46), texture (4.48), general acceptability (4.61) by consumers (Figure 2). The guava leaves tea sample also remained the least preferred by participants in terms of general appearance (4.6) and aroma (4.51). The taste of Chinese tea was disliked and least preferred (4.47) by participants. Among all the lowest preferred samples, the increasing order of dislike is as follows: guava leaves < Chinese tea $<$ lemongrass. Surprisingly, the clove tea 
sample remained desirable, appealing, and most preferred by participants in all the sensory evaluation parameters (Figure 2).

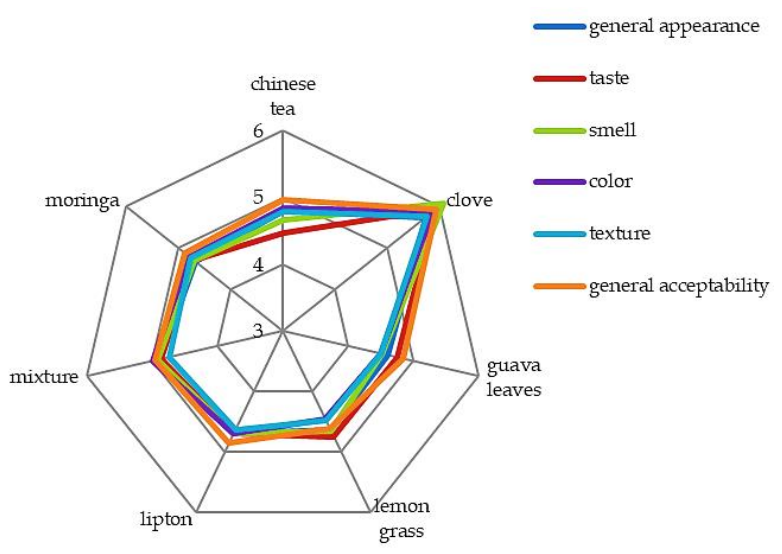

Figure 2. Web diagram for mean sensory scores of tea samples. 1: strongly disliked; 2: moderately disliked; 3: slightly disliked; 4: indifferent; 5 : slightly liked; 6: moderately liked; 7: strongly liked ${ }^{15}$

No previous studies were found in the literature which used clove tea for sensory evaluation, thereby making this is the first study to incorporate it. A possible explanation for variation and the least preferred lemongrass tea sample might be that aroma-producing compounds were volatile and may combine with other constituents while preparing the sample ${ }^{16}$. Also, participants were probably not familiar with lemongrass tea and would have expected sweet taste and an appealing black color ${ }^{17}$.

Furthermore, a previous study conducted by Ochanda et al. ${ }^{18}$ obtained similar results. They also reported that the panelist least preferred the lemongrass tea sample in terms of color, texture, and overall acceptability, consistent and in agreement with the results obtained from our study. This study has shown that the clove tea sample we formulated was most acceptable and preferred by the participants compared to commercially available branded tea samples.

To our knowledge, this is the first study to demonstrate the consumer acceptability of tea prepared from the clove. Analysis of antioxidant and nutrient composition concludes that Clove tea samples had a higher concentration of antioxidants and nutrient composition than other herbal tea, which suggests being responsible for sweet and high sensory attributes and flavor of the tea sample ${ }^{19}$. The high antioxidant composite of these tea samples produces tea of better quality to enhance health benefits. This will also encourage tea products and generate employment for many, culminating in economic development as tea import also reduces ${ }^{20}$.

\section{CONCLUSION}

Clove tea samples were the most preferred color, aroma, taste, texture, general appearance, and general acceptability. Lemongrass was the least accepted and preferred in terms of color and texture. The participant did not prefer the aroma and general appearance of guava.

\section{REFERENCES}

1. Dar RA, Shahnawaz M, Qazi PH. General overview of medicinal plants: A review. J Phytopharmacol. 2017;6(6):349-51.

2. Pieroni A, Torry B. Does the taste matter? Taste and medicinal perceptions associated with five selected herbal drugs among three ethnic groups in West Yorkshire, Northern England. J Ethnobiol Ethnomedicine. 2007;3:21. doi:10.1186/1746-4269-321

3. Adnan M, Ahmad A, Ahmed A, Khalid N, Hayat I, Ahmed I. Chemical composition and sensory evaluation of tea (Camellia sinensis) commercialized in Pakistan. Pak J Bot. 2013;45(3):901-7.

4. Chaturvedula VSP, Prakash I. The aroma, taste, color and bioactive constituents of tea. J Med Plants Res. 2011;5(11):2110-24. doi:10.5897/JMPR.9001187

5. El Sheikh R, Amin AS, Atwa MA, Gouda AA, Abdullah AA. Determination of Phenolic Components and Antioxidant Activity of Some Egyptian Tea Samples. Int J Pharm Pharm Sci. 2015;7(4):198-202. 
6. Khan N, Mukhtar H. Tea and Health: Studies in Humans. Curr Pharm Des. 2013;19(34):6141-7. doi:10.2174/1381612811319340008

7. Hajdari A, Mustafa B, Hyseni L, Bajrami A, Mustafa G, Quave CL, et al. Phytochemical Study of Eight Medicinal Plants of the Lamiaceae Family Traditionally Used as Tea in the Sharri Mountains Region of the Balkans. ScientificWorldJournal. 2020;2020:4182064. doi:10.1155/2020/4182064

8. Huang D, Ou B, Prior RL. The chemistry behind antioxidant capacity assays. J Agric Food Chem. 2005;53(6):1841-56. doi:10.1021/jf030723c

9. Drewnowski A, Gomez-Carneros C. Bitter taste, phytonutrients, and the consumer: a review. Am J Clin Nutr. 2000;72(6):1424-35. doi:10.1093/ajen/72.6.1424

10. Tang GY, Meng X, Gan RY, Zhao CN, Liu Q, Feng YB, et al. Health Functions and Related Molecular Mechanisms of Tea Components: An Update Review. Int J Mol Sci. 2019;20(24):6196. doi:10.3390/ijms20246196

11. Bhuyan LP, Borah P, Sabhapondit S, Gogoi R, Bhattacharyya P. Spatial variability of theaflavins and thearubigins fractions and their impact on black tea quality. J Food Sci Technol. 2015;52(12):7984-93. doi:10.1007/s13197-015-1968-z

12. Zou G, Xiao Y, Wang M, Zhang H. Detection of bitterness and astringency of green tea with different taste by electronic nose and tongue. PLoS One. 2018;13(12):e0206517.

doi:10.1371/journal.pone.0206517

13. Lee J, Chambers DH. Sensory descriptive evaluation: brewing methods affect flavour of green tea. Asian J Food Agrolndustry. 2009;2(4):427-39.

14. Nakagawa M. Contribution of Green Tea Constituents to the Intensity of Taste Element of Brew. Nippon Shokuhin Koggyō Gakkaishi. 1975;22(2):59-64. doi:10.3136/nskkk1962.22.59

15. Granato D, Masson ML, Ribeiro JCB. Sensory acceptability and physical stability evaluation of a prebiotic soy-based dessert developed with passion fruit juice. Ciênc Tecnol Aliment. 2012;32(1):119-25. doi:10.1590/S0101-20612012005000004

16. Dhifi W, Bellili S, Jazi S, Bahloul N, Mnif W. Essential Oils' Chemical Characterization and Investigation of Some Biological Activities: A Critical Review.
Medicines.

2016;3(4):25.

doi:10.3390/medicines3040025

17. Lonkar PB, Chavan UD, Pawar VD, Bansode VV, Amarowicz R. Studies on Preparation and Preservation of Lemongrass (Cymbopogon flexuosus (Steud) Wats) Powder for Tea. Emir J Food Agric. 2013;25(8):585-92. doi:10.9755/ejfa.v25i8.15218

18. Ochanda SO, Wanyoko JK, Ruto HK. Antioxidant Capacity and Consumer Acceptability of Spiced Black Tea. J Food Res. 2015;4(6):104-12.

19. Yashin A, Yashin Y, Xia X, Nemzer B. Antioxidant Activity of Spices and Their Impact on Human Health: A Review. Antioxidants. 2017;6(3):70. doi:10.3390/antiox6030070

20. Chacko SM, Thambi PT, Kuttan R, Nishigaki I. Beneficial effects of green tea: A literature review. Chin Med. 2010;5:13. doi:10.1186/1749-8546-5-13 